\title{
A Survey of English Classroom Interaction in Guilin Normal College
}

\author{
Ma Xiaoyun \\ Department of Foreign Languages and \\ Tourism, Guilin Normal College, \\ Guilin, Guangxi. PR.China
}

\author{
Long Xiaoming \\ Department of Foreign Languages and \\ Tourism ,Guilin Normal College, \\ Guilin, Guangxi. PR.China)
}

Abstract - Humanistic psychology stresses that both cognition and affection should be incorporated in human's wholesome and comprehensive development. In guidance of the humanistic psychology, a new round of reform in College English Curriculum Requirement has advocated. English classroom teaching has changed from an emphasis on the teacher-centered

teaching, examination-oriented teaching, grammar and vocabulary-based approaches to a concern with the learner-centered, humanistic, quality-oriented and communicative approaches. The survey was conducted among teachers and students who are major in the Hotel Management to get a better understanding of the current situation of English classroom interaction in Guilin Normal College. 100 students and 15 teachers subjects were engaged in the study, and interviews were also carried out with 20 students and 6 teachers randomly chosen from those questionnaire subjects. Based on these findings, some suggestions are put forward for the college teachers and students to enhance the effectiveness of English teaching and learning.

Key words: Cognition; Affection; Classroom interaction; Normal College

\section{Introduction}

The acquisition of a language requires English learners master language vocabulary and grammar, the most important is the ability of using it. Nowadays, many Chinese students have good knowledge of English grammar, vocabulary structure, but relatively weak at oral and listening proficiency. This result comes from the traditional English teaching method. During the class, most of Chinese teachers spend almost all teaching hours to deliver the linguistic knowledge instead of giving students change to think and ask questions. It causes teachers and students separated psychologically. Facing the remarkable drawback of traditional English teaching, a new round of reform in College English Curriculum Requirements has advocated. The new round reform arouses English teachers gradually change teaching method of focusing on teacher-centered to a learner-centered, humanistic and communicative approaches.

Language learning is very complex psychological process, throughout the process of foreign language learning, students are influenced by the intelligence quotient, as well as the emotional intelligence. Nowadays, the classroom interaction approach was widely used to improve students' interests in English learning since teachers and students are both participants, their cognitive and emotion involved in the classroom. To some extent, cognitive and emotion 
involvement in both of two parties can help teacher to understand student' needs, sensitivity and feelings. Meanwhile, positive effective messages delivery in the classroom interaction can enhance the students' self-esteem since their beliefs in their abilities strongly influence their performance. Large amount of theoretical researches were done by scholars to indicate that classroom interaction as one of the most important factors in second language acquisition (SLA).

\section{Literature Review}

\subsection{Definitions of Classroom Interaction}

Chaudron (1986:432) refers to classroom interaction as "the medium by which much teaching takes place and during which students demonstrate to teachers much of what they have learned".

Allwright \& Bailcy (1991) argues the real process of teaching is classroom interaction which is regarded as "living interpersonal interaction".

Yang Shuoguo (2009) views classroom interaction is two-way communication and negotiation on the basis of democracy and equality.

Li Hong (1998) views the interaction phenomenon in classroom teaching include the suggested that infection, imitation, cooperation, competition and even conflict.

Researchers have defined classroom interaction from different perspectives, but still, they have some points in common:

(1) Classroom interaction is a dynamic, creative, and exploratory process carried out between teacher and students or among students.

(2) Classroom interaction is the process of "constructing" which focus on teachers and students sharing the thoughts and wisdom.

(3) Classroom interaction focuses on student-centered, which the relationship between the teachers and students are established on the basis of equality.

(4) Affective factors play important role in the process of interaction. Classroom interaction will not occur without emotion involved.

Based on the statements above, it can be concluded that classroom interaction is

a dynamic, creative and exploratory process in which the teacher and students share the emotion, experience and knowledge by means of using verbal and nonverbal messages . Both of two parties seek for harmonious environment.

\subsection{Features of Classroom Interaction}

We can see that interaction between the teacher and students can be regarded as an important manifestation of human interpersonal relationships. Its features are:

(1) Two-Way Operation and cognition focus

Classroom teaching is not unidirectional activity, but a two-way communication between teachers and students. It was clarified in Brown'definition (2001:159) "the interaction as "the collaborative exchange of thoughts, feelings, or ideas between two and more people resulting in reciprocal effect to each other". In the practice of classroom interaction, both of two parties highly involve in the activity which the role of students in the class is highlighted particularly. They are the dialectical unification relations.

Brown (2003:159-160) argues "cognitive principles include automaticity, meaningful learning, intrinsic motivation, and strategic investment, which are closely related to mental and intellectual functions, and meet the needs of students' cognitive development". To some extent, students' cognitive development can be achieve in the Classroom interaction approach since the teacher creates more authentic situation which closely related to students' daily life to enable 
them to use the language efficiently.

(2) Affective Homogeneity and Mutuality

Affection is seen as a filter which impacts the amount of input in learning. The correlation between the affective factors and success in second language acquisition has been proved by researches. Krashen's Affective Filter Hypothesis(1986) indicate that the importance of affective factors in the second language acquisition. In the practice of teaching, teachers apply for positive verbal and non-verbal language can create the best learning environment for building student's self-confidence and self-esteem.

(3) A Democratic and Equal Relationship

According to Brown (2003:160) "the complexity of interaction entails a long developmental this development. And the role of teachers' feedback is crucial to the developmental process". In the process of interaction, the relationship between the teacher and students is established in basis of democracy and equality which offer students more opportunity to negotiate with others and teacher. The teacher is patient and tolerant with students' English learning by using positive comments and praiseful language can form positive emotion attitude and values.

\subsection{Current Studies on Classroom interaction from aboard and home}

The theoretical research on the English learning and teaching from the angle of humanism was all -around developed by linguisticians since humanism in particular has been dramatically influential in both educational psychology and language teaching in the early 1960 s. From that time on, interaction in language has attracted the attention of many foreign researchers in the field of language learning and acquisition which the focus of teacher-student relationship, teacher's role and student affective were highlighted. A large number of researches in SLA have brought to light the significance of "classroom interaction" researchers such as Allwright (1984, 1988, 1991), Krashen (1981), Swain(1983, 1985), Pica(1987), Ellis(1985, 1994), Larsen-Freenman (1986), Richards and Lockhart (1994), Long (1985, 1996), have provided extensive descriptions and reviews of the major theories of second language acquisition.

The research on classroom interaction in China benefits a lot from the studies abroad. Until recently, many Chinese researchers and EFL teachers have begun to realize the important place of classroom interaction in EFL teaching and learning. Some Chinese scholars have also done a lot of researches on classroom interaction from various perspectives.

In the field of sociology, Wu Kangling (1988) analyzes in his book Educational Sociology basic roles of education, main social organizations and key social activities on education. In the field of psychology, the researchers focus on interaction content and pedagogical researchers prove and explain the phenomenon of interaction by studying the related theories.

Yuan Weixin (2002) made an analysis of the definition of interaction, and tried finding out the elements of impacting on and boosting interaction. Chen Xiaojiao (2001) and Yang Xueyan (2003) told us the current situation and strategies of English classroom interaction. Hai Chunhua (2005) researched human interactive relationship between teacher and students, Hai indicates that teacher-student and student-student relationship is very important part of teaching activities, as well as Hai emphasized that the human relationship is greatly influenced by teacher's teaching philosophy.

As for the teacher's role in classroom interaction, Li Guangqin (2005) held that the 
teacher's role as a mediator in student-centered classroom interaction. Kang Xiaorong (2004) held that the teachers should be "a constructor, a participant and a researcher."

Shen Guipeng (1997), Qiu Wei \& Zhang Jie (2006), Wu Defang (1999) have done some researches on teacher behavior in the class.

Zuo Bin (1998) gives an analysis of the definition, features and nature of teacher-student classroom interaction.

Lin Zhengjun, Liu Yongbing \& Wang Bing (2009), as the latest researchers, review all the research articles and these from 1994 to 2007 in China by discussing their achievements and problems in this field form the perspectives of research methods and research contents (Cited in Zhang, 2010) .

Furthermore, an investigation of affective and personal factors and its relationship to in language learning has interested some Chinese scholars. Shi Yongzhen (2000) analysis the relationship between the motivation and effectiveness of English learning. Guo shucai (2002) analyzes the relationship between the affective factors and language learning from the cognitive and emotional perspective, also the studies focus on teacher-student affective interaction in the process of language teaching. Books about affective teaching were published by Zhu Xiaoman (1993) and Lu Jiamei (1993, 2002).

\section{Methodology}

The survey was conducted at the Department of Foreign Language and Tourism of Guilin Normal College. 100 students subjects were selected from Grade 2 major in Hotel Management. On the other hand, 20 subjects in total were chosen for interviewing. 15 teachers subjects involved in the research already have almost ten years of teaching experiences. Descriptive survey by means of a questionnaire and survey interview was employed altogether in the study. Qualitative analysis used for questionnaire and interview part.

English classroom interaction questionnaire includes 26 items randomly distributed. This questionnaire measures (1) the general picture of classroom interaction in Guilin Normal College; (2) the attitude towards classroom interaction in Guilin Normal College; (3) the recognition of classroom interaction in Guilin Normal College; (4) the expectation of classroom interaction in Guilin Normal College. The total 26 items are rated on a five-point Likert scale ranging from SA (Strongly agree) to SD (strongly disagree), In addition, The open-ended questions used in the interviews. Contents of interview similar to the questionnaires but assist to get more detail information for questionnaire.

\section{Discussion based on research findings}

The finding shows that classroom interaction is welcomed by teachers and students. They believe that classroom interaction can create a relaxed and harmonious environment where everyone fully participates in the interactive activities and the relationship between the teachers and students have been improved. Also, it is effective for improving students' English efficiency, as well as the improving their interests and concentration on English studying. However, the effectiveness of classroom interaction expected by students are:

Firstly, taking consideration of the duration of teaching time, size of class and level of student's English proficiency, class discussion and asking-answering questions are the common approaches are mainly used by teachers to conduct the interaction activities. However, there are not all students really take part in the activities since some students think it bored or interaction approaches are too simple. Except the 
common type of classroom interaction activity being used in the class, students expect the classroom activities should be created in different ways, for instance, pair work, role play and presentation for the all the students in all level, or teachers can ask students to arrange the mini movie show based on the story in the textbook.

Secondly, teachers' behavior and affection will relate to the students' second language acquisition, positive language usage can arouse students' involvement in English learning, otherwise, it can decrease the students' confidence. $60 \%$ of students subjects think teachers should use more praised words by saying "you can do it, try it" or you will do great job", in particular, an positive assessment and advise should be given to students when students make mistakes, teachers should give poor English level students more encouragement to speak out instead of ignoring them. Effective communication by means of verbal and non-verbal can help students who are equipped with high level of confidence to join the English learning.

Thirdly, on the basis of learner-center concept, student' interests and mental needs should be considered more. The design of classroom interaction content should be fit students in different English level. According to the students' feedback, some teachers like to download the courseware from the internet which the activity a bit upper than their English level, students gradually lose interests in learning English or passively join the class activity. Therefore, it is important for teacher to identify the sources that will close to students' life experience.

\section{Conclusion}

Findings of the research work conducted among the students obviously pointed that the classroom interaction in an effectiveness teaching method to arouse the students' interests in
English study. To conduct or perform the classroom interaction activity effectively, college, teachers and students should work together.

Firstly, according to the humanistic psychology, both cognition and affect should be incorporated in human's wholesome and comprehensive development. Students' comprehensive development should be priority of goal of teaching. School should encourage teachers to innovate teaching approaches to develop students' comprehensive skill.

Secondly, Teachers should manage the relationship between the language input and output. In the process of English teaching, offering a reasonable content of classroom interaction input and affection input are the vital foundation for helping students to actively involve in the classroom activities and learn effectively, developing their personal identity and self-esteem, Meanwhile, teachers give students comprehensible input while also give students chances to speak out their mind at the moment. Teachers possibly maximize the participant of students by arranging different types of activity. Play roles, pair work, tell stories and make presentations are the approaches can increase students' language store as they listen or increase the language output by negotiating with of their peers.

Thirdly, classroom interaction focus on student-centered, which the relationship between the teachers and students was establish on the basis of equality, and teachers are more likely to give priority to students' needs. So the role of teachers and students in the interactive class should differ from the traditional class. The role of teachers can be a facilitator, resource-provider which makes learning easier for students, to help them clear away roadblocks, to find shortcuts, to negotiate rough terrain.

Fourthly, collaboration is good way for 
students to develop English knowledge. According to Interactionism theories, when students are given chance to join interactive class activities, they will fully apperceive input and use input modification devices to make the input comprehensible. Classroom interaction create a harmonious atmosphere which students should actively learn to cooperate with their peers and teachers

Lastly, students should make correct attitude towards the role in the class since the relationship between the teachers and students has been established on the basis of equality, and teachers are more likely to give priority to students' needs. They can treat the teacher as a friend, helper and guider instead of a controller.

\section{Acknowledgement}

This paper is one of the research achievements of the project supported by Guangxi provincial Education Department. (Project No. 2013JGZ172)

\section{References}

[1] Allwright, D. (1984). Why don't learners learn what teachers teach? - The interaction hypothesis [M]. In Singleton, D.M. and D. G. Little. Language learning in formal and informal contexts, Irish Association for Applied Linguistics. Dublin: IRAAL.3-18. .

[2] Allwright, D. \& K. M. Bailey. (1991). Focus on the Language Classroom [M].Cambridge: Cambridge University Press.

[3] Allwright, R.L. (1984).The importance of Interaction in Classroom Language Learning [J]. Applied Linguistics (2): 156-169. 